\title{
A Study of Primary Health Care at Divulje Barracks, Split on Operation Resolute (Bosnia)
}

\section{Sqn Ldr DA Winfield}

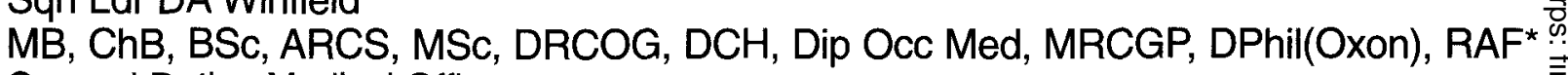
General Duties Medical Officer

No 3 Casevac Sqn, Divulje Barracks, Royal Air Force, Medical Centre, Split BFPO 544

SUMMARY: A study of primary health care was undertaken at Divulje Barracks, Split, during Operation Resolute, $\frac{\overline{\frac{D}{5}}}{\bar{T}}$ 1996. A total of 1581 patients were seen during weeks 3 to 10 of the operation (day ' 13 ' to '70'). The number of $\stackrel{\square}{\Omega}$ consultations was greater for the first half of this period than for the second, and there were two early epidemics, one $\stackrel{\infty}{\mathrm{N}}$ of respiratory disease and the other of enteric disease. Occupational and road traffic accident injuries were more $\vec{\circ}$ common in the first 6 weeks and then declined with time.

\section{Introduction}

Historical Background to Operation Resolute

Since 1991 the Former Republic of Yugoslavia (FRY) had been engaged in a civil war. The presidents of the three warring factions were eventually persuaded to sign a peace accord, known as the 'Dayton Agreement', on 14th December 1995 and seven days later, on 'D Day' the 20th December, NATO forces (IFOR) took over from the United Nations' peace keeping force and began their role of enforcing this agreement in an operation involving troops from many nations. In fulfilment of its responsibility to control an area of Bosnia-Herzegovina (BH) called Multinational Division Southwest (MND SW) the UK provided a force in an operation called 'Operation Resolute'.

\section{The Primary Health Care Team at Split}

British troops deployed to FRY in late December 1995 and early January 1996, and medical assets had, therefore, to be provided. One of the primary health care (PHC) assets was placed at Divulje Barracks $20 \mathrm{~km}$ from Split, a port on the coast of Croatia. The primary health care team (PHCT) was taken from the RAF No. 3 Casualty Evacuation Squadron (3 Casevac Sqn).

\section{The Practice Population}

Unlike for a practice in the United Kingdom (UK), whose population can be defined precisely, the absolute number of patients in Divulje Barracks (referred to as Split in this study) could not be determined accurately. The population could be defined generally as those UK personnel located in and around Divulje Barracks and the town of Split; British personnel in other units in outlying positions for whom Split would be the nearest medical centre; a smaller number of military personnel from other nations in the same area (for example Holland, New Zealand, Canada, etc); and civilians, including Croats, and other legitimate British or foreign nationals working on behalf of, or for, the United Nations or IFOR from Split (for example interpreters, press officers, etc). The population changed daily.
Aim of this Study

The aim of this study was to give a semi-quantitative profile of PHC in Split under operational conditions.

\section{Methods}

Data was collected for 7 weeks commencing on 1 st오 January 1996, the date when 3 Casevac Sqn began its tour, covering the period between 'week 3' and 'week 10' following 'D Day' (days ' 13 ' to '70').

A daily record was made of each patient's attendange $\overrightarrow{7}$ and his reason(s) for consulting. Using the J95 Health Da䅦 $\mathbb{O}$ Collection System of epidemiological surveillance, each illness or injury has been classified according to twenfy three events and codes (1). For simplicity, only $\vec{a}$ proportion of the data collected in this system will presented here, and, because of the small numbers of cas involved in some categories, several categories have bee combined for ease of presentation, e.g. asthma wi respiratory diseases, and intestinal infections with peptic disease. The following are the categories presented here:

\begin{tabular}{|c|c|}
\hline Disease or Injury & J95 Code \\
\hline Intestinal infections \& peptic ulcer & 1,10 \\
\hline Syphilis and STDs & 2 \\
\hline Mental disorders & 5 \\
\hline Respiratory diseases and asthma & 7,8 \\
\hline Dental disease & 9 \\
\hline Gynaecological & 12 \\
\hline Dermatology & 13 \\
\hline Other diseases & 12,22 \\
\hline RTA injury & 17 \\
\hline Other injury - sport/occupational & $14,15,16$ \\
\hline
\end{tabular}

Some conditions reportable using the J95 system were not experienced in this practice and have therefore not 을 been given here. Thus, for example, no information is $>$ presented on injuries when due to operations and war으․ (code 19), disease due to reduced temperature, heat or light (code 20), complications of medical care (code 21), and ${ }^{\circ}$ nuclear/biological/chemical warfare symptoms (code 23 ). $\stackrel{\text { O }}{ }$

The practice was not computerised and all consultations 
were recorded on the usual forms (F Med 5s). Similarly, prescriptions were issued on Med 296s. Numerical analyses was undertaken manually, and graphs were drawn using Microsoft PowerPoint.

The drug details have been calculated using the first 500 prescriptions between the 1st and 15th February 1996. The costs of drugs have been calculated using the concept of basic net prices used by the British National Formulary Number 30.

\section{Results}

The Practice Population

The number of personnel varied each week. On average there were about 2500 people in the Split component of MND SW, of whom there were about $220 \mathrm{RAF}$ and 60 Royal Navy (RN) personnel; about 5\% were female (information supplied by G1). A comparison of returns from $\mathrm{G} 1$ showed that about $70 \%$ (1750) of the personnel were in Divulje Barracks, and the remaining 30\% (700) were covered by 5 Field Ambulance ( 5 Fd Amb). This gives figures of about $84.1 \%, 12.5 \%$ and $3.4 \%$ of the population respectively for the Army, RAF and RN, and about 100 females.

\section{Number Of Patients Seen}

A total of 1581 patients were seen. The distribution between services was: Army $79.5 \%$, RAF $12.5 \%, \mathrm{RN}$ $2.75 \%$, and others $5.25 \%$.

\section{The Number of Consultations Per Day}

Figure 1 shows the number of consultations made each day. The number for January rose $42 \%$ from 43 on the 2 nd day to a maximum of 61 on the 5 th day. It then fell to 28 on the 19th and was maintained at between 20 and 30 for the rest of January (with the exception of a peak of 46 on 29th January) and all of February.

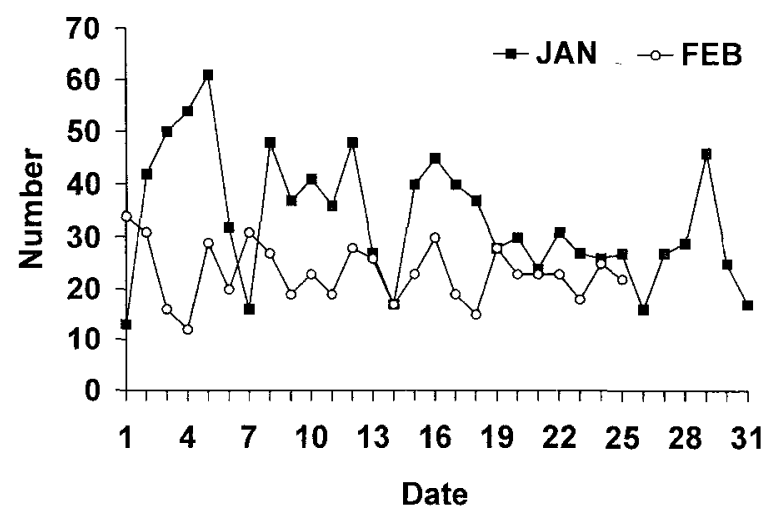

Fig 1. Number of Patients Seen Per Day

The Weekly Number of Consultations

Figure 2, 3\&4 shows that the number was greatest in January, with a gradual fall thereafter.

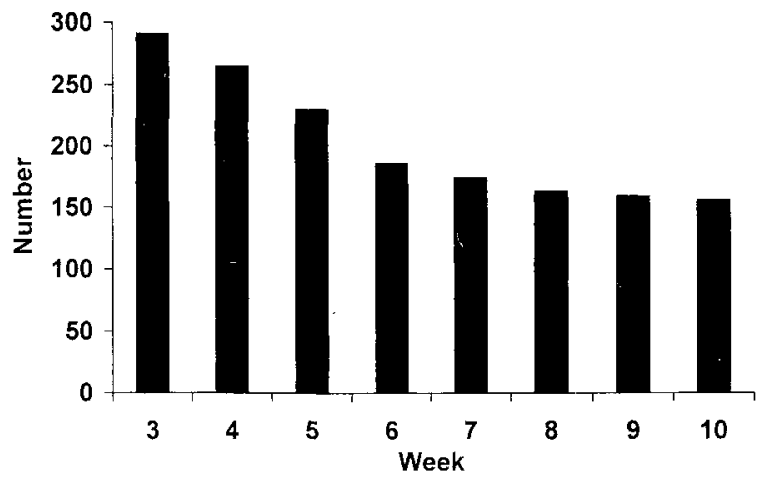

Fig 2. Weekly Number of Consultations

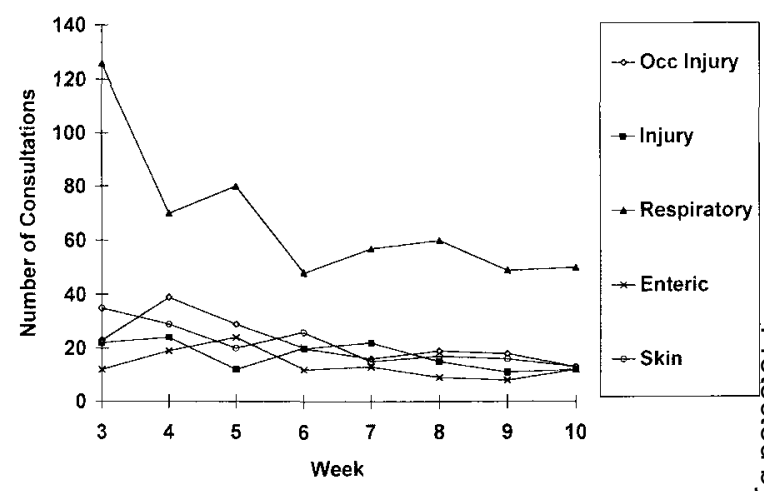

Fig 3. Weekly Distribution of Diseases

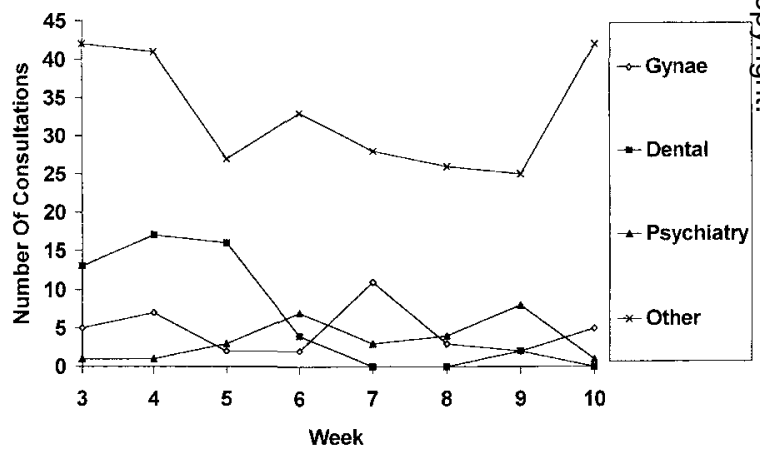

Fig 4. Weekly Distribution of Diseases

The Weekly Number of Consultations With Different Injuries And Diseases

a. Total Injuries

Looking at total injuries as a group there were consistently at least 40 consultations per week (Fig 5). There were more during January than February.

\section{b. RTAs}

Eighteen patients consulted with injuries sustained in RTAs (Fig 6). The worst week was week 4 when 7 people were seen.

\section{c. Occupational Injury}

Figure 7 shows a rise of $70 \%$ from 23 in week 3 to 39 in week 4 , followed by a gradual fall to between 15 and 20 


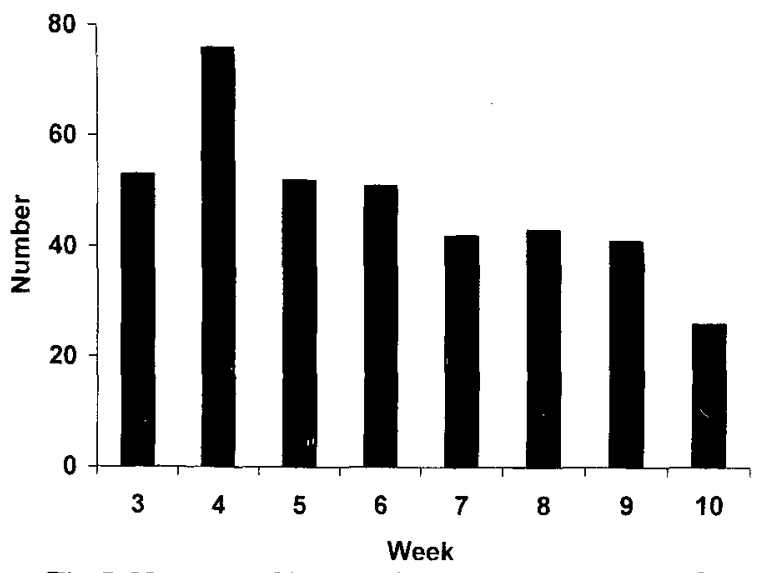

Fig 5. Number of Injury Consultations Per Week

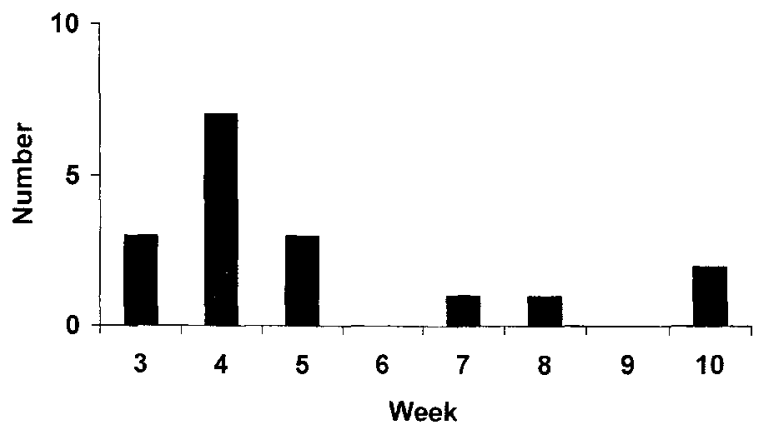

Fig 6. Weekly Number of RTAs

from week 6 onwards.

d. Sport Injuries

Figure 8 shows that, in general, there was a gradual increase in the weekly number of consultations with sport injuries.

e. Other Injuries

No clearly defined trend could be determined for 'other' injuries (Fig 9).

f. Total Disease

Figure 10 shows a fall in the total number of disease consultations from a peak of 237 in week 3 to 123 in week 10 , about $50 \%$ fewer.

\section{g. Respiratory Disease}

In week 3 over 120 weekly consultations with respiratory disease were made (Fig 11). The number dropped markedly (by about $40 \%$ ) in the 5th and 6th weeks, to between 70 and 80 , and then settled further over the next 5 weeks to about $40,33 \%$ of its peak value.

h. Enteric Disease

Figure 12 shows an increase in weekly consultations from 12 in week 3 to 24 in week 5 , a rise of $100 \%$. Thereafter, the number fell quickly to about 10 by week 8 . i. Skin Disease

The weekly number of consultations with skin disease was initially 35, and fell thereafter to 13 (Fig 13).

j. Gynaecological

Figure 14 shows that there were 33 consultations with

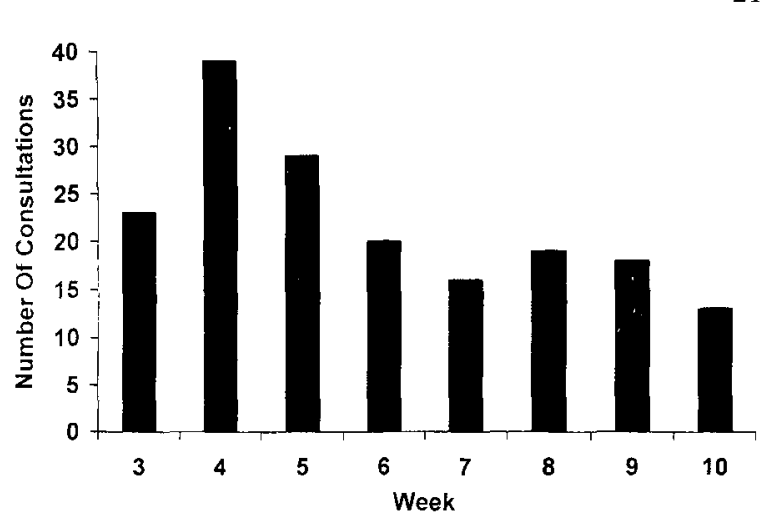

Fig 7. Number of Consultations with Occupational Injury Per Week

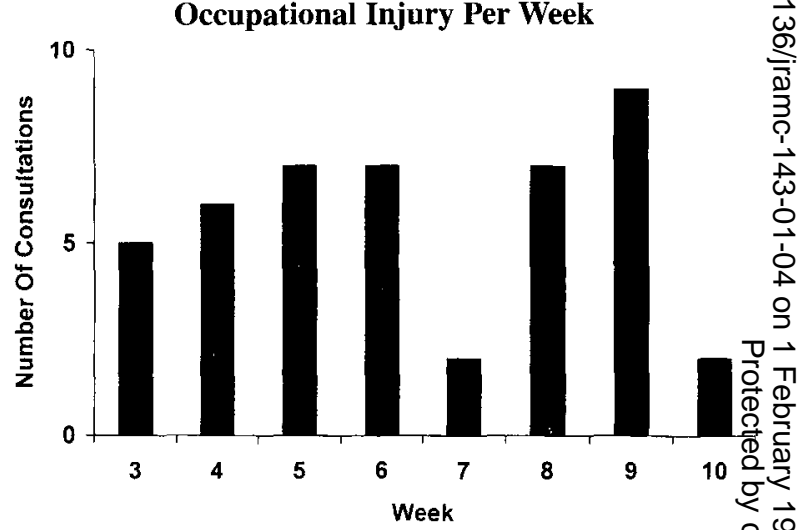

Fig 8. Number of Consultations with Sport Injury Per Week

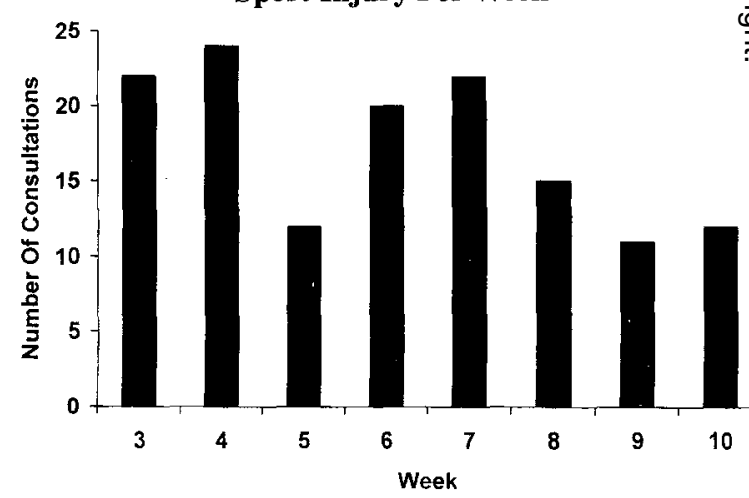

Fig 9. Number of Consultations with Injury Per Week

gynaecological problems.

k. Dental Disease

Figure 15 demonstrates a marked weekly variation in the consultations.

1. Other Disease

There were consistently more than 25 consultations per ? week with 'other' diseases (Fig 16). In weeks 3 and 4 the $N$ number exceeded 40 per week, but there appeared to be a స్ట decline from week 5 , with the number settling at about 25, , 


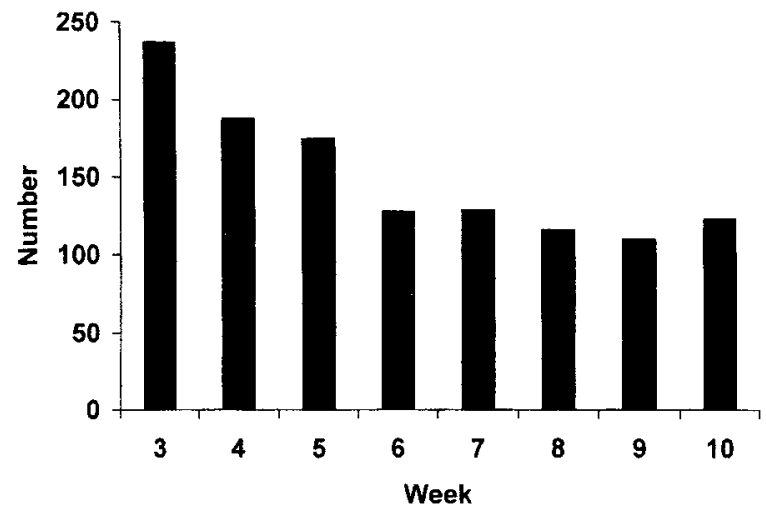

Fig 10. Number of Disease Consultations Per Week

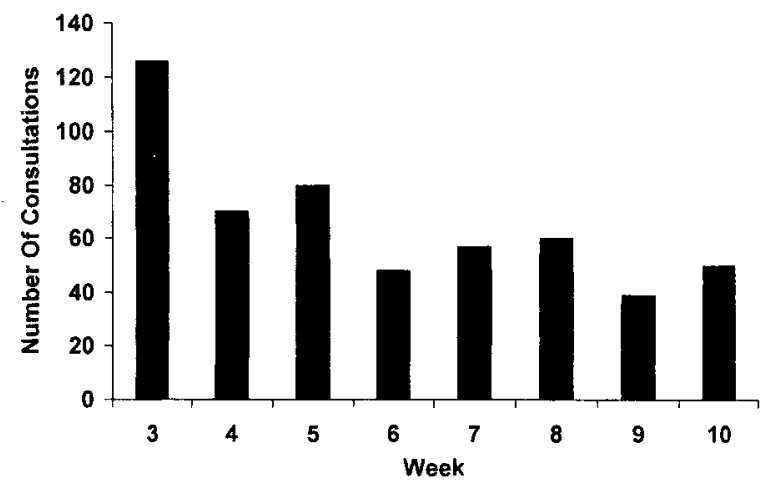

Fig 11. Number of Consultations with Respiratory Disease Per Week

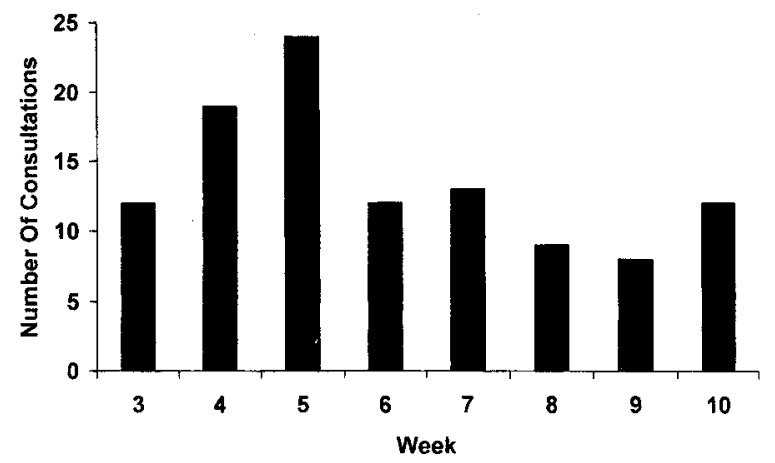

Fig 12. Number of Consultations with Enteric Diseases Per Week

although in week 10 there were 42 .

m. STDs

Twenty-five cases were seen.

n. Psychiatric Illness

There was a marked variation in weekly rate (Fig 17). Overall, numbers were small.

\section{Simple Analysis Of Drugs Prescribed}

The number of prescriptions for the 10 most commonly prescribed drugs is given in Figure 18, which demonstrates

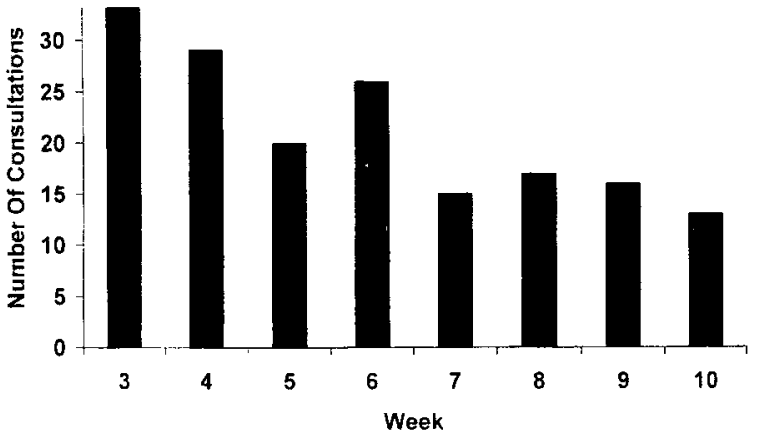

Fig 13. Number of Consultations with Skin Disease Per Week

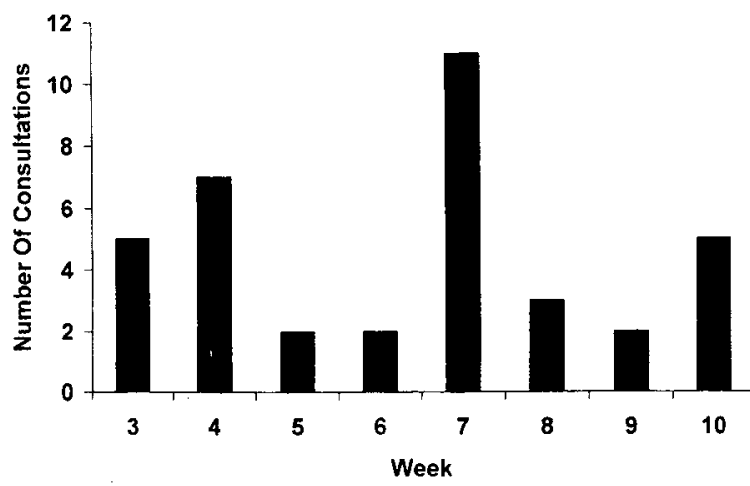

Fig 14. Number of Consultations with Gynaecological Disease Per Week

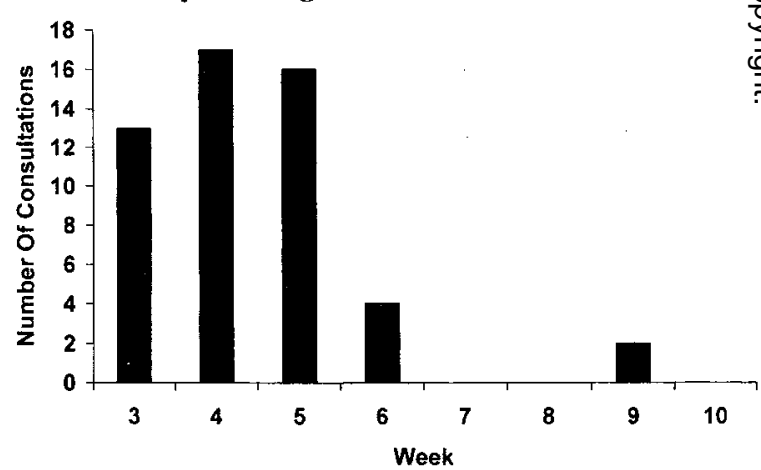

Fig 15. Number of Consultations with Dental Disease Per Week

that pseudoephedrine (sudafed), aspirin, codeine linctus and paracetamol were the 4 most commonly prescribed drugs. The most commonly used NSAID was ibuprofen, and the 2 most frequently prescribed antibiotics were amoxycillin and ampicillin. Chloromycetin eye treatment was the 10th most commonly used drug.

Figure 19 shows the proportion of drugs prescribed by drug class. As the numbers of prescriptions issued for gynaecological disorders, ENT disease and the cardiovascular system were small, these have been combined as a single category called 'other'. It can be seen 


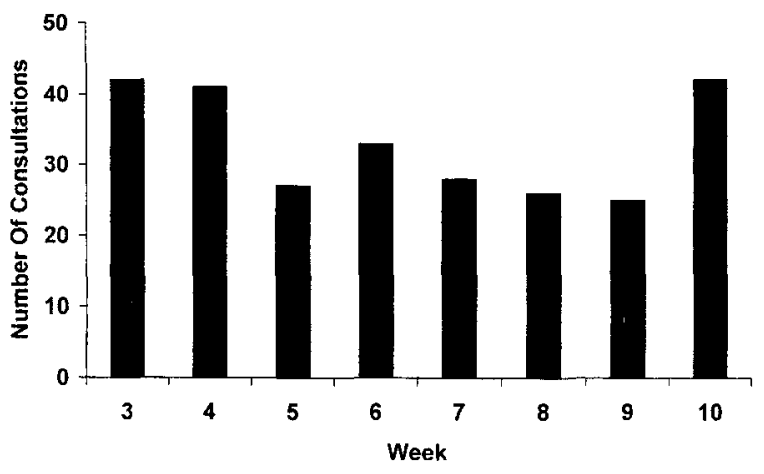

Fig 16. Number of Consultations with Other Diseases Per Week

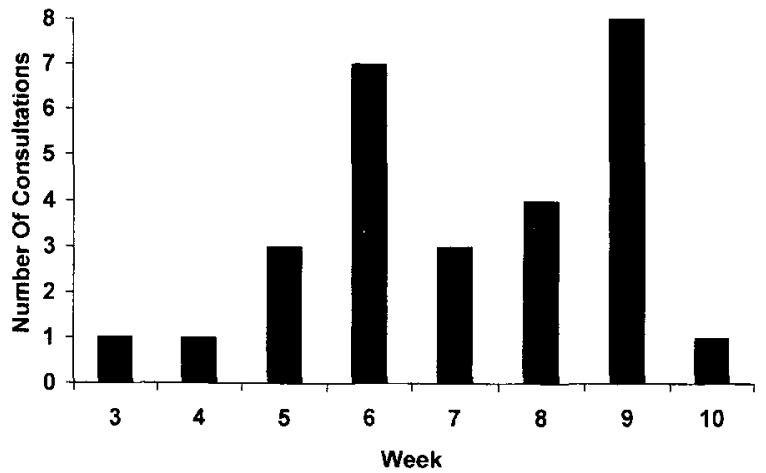

Fig 17. Number of Psychiatric Consultations Per Week

that drugs for infections were the most common (25\%), followed by drugs for the respiratory system (23\%) and the central nervous system $(21 \%)$.

It was shown that the average cost per prescription was $£ 2.02$, and the average cost per day was $£ 28.70$. Prescribing costs by drug class, given in Figure 20, were greatest for drugs used in infections, followed by those for musculo-skeletal problems.

\section{Discussion}

Unfortunately the practice population could not be determined precisely. It was estimated to be about 1750 . The relative proportions of patients seen in the 3 Services corresponded closely with the relative proportions given by G1 for MND SW and this suggests that the estimate is fair, provided that it is assumed that personnel in the different services consult at similar rates. Unfortunately, however, the uncertainties in calculating the size of the practice population makes it difficult to provide credible prevalence and incidence data in this practice, and makes extrapolation to other operations difficult.

The number of consultations was greatest in the early phase of the operation, being greatest in January and falling steadily during February, after about week 6 . This observation is similar to data collected from other practices in $\mathrm{BH}$ (1) it could have an impact on the level of medical

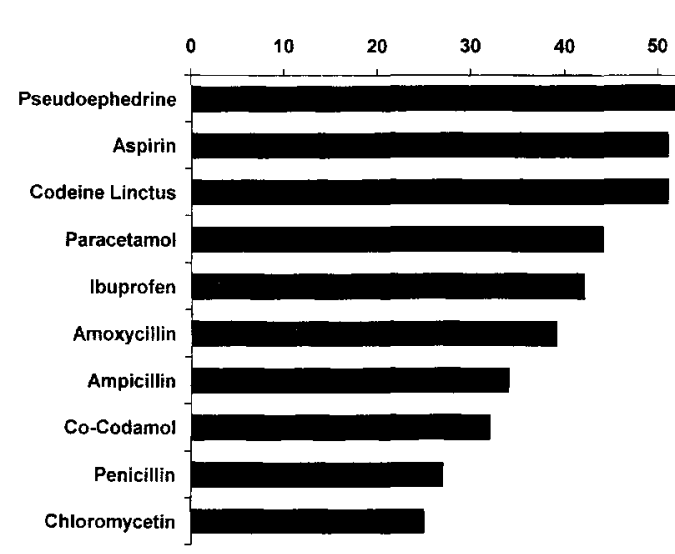

Fig 18. Number of Prescriptions Issued Between 1-15 February 1996

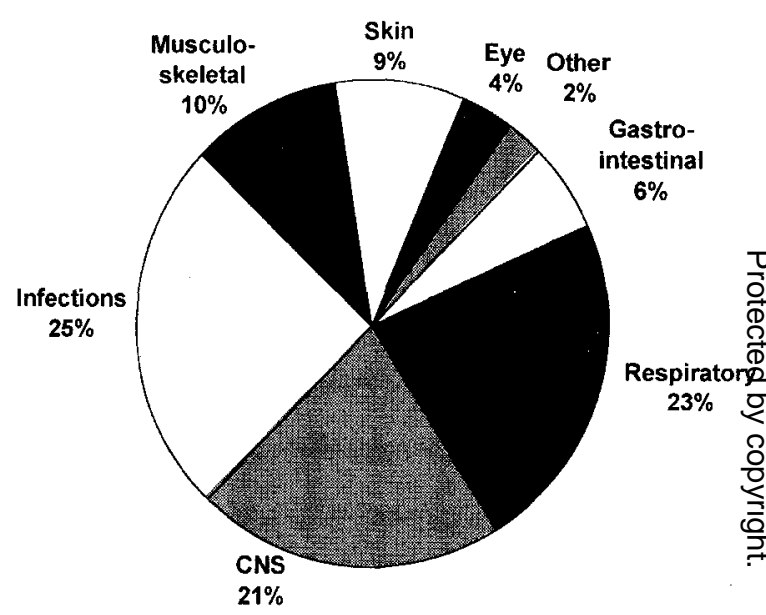

Fig 19. Proportion of Prescriptions by Drug Class

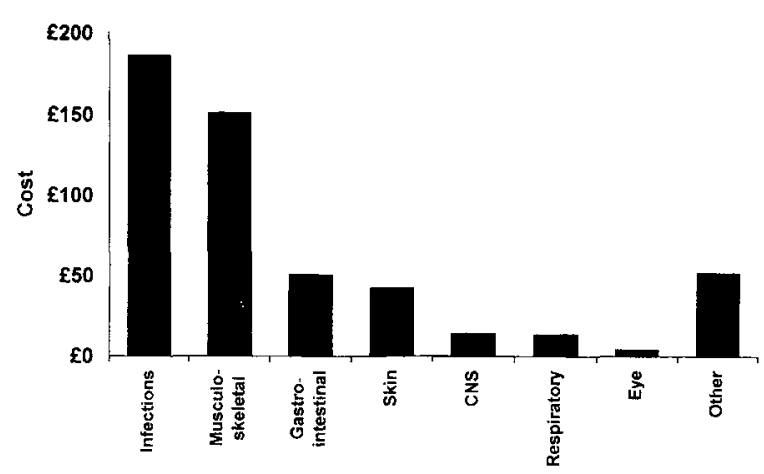

Fig 20. Prescribing Costs - by Drug Category

manning at the outset of an operation, when most of the medical input is required.

The large number of injuries in the first few weeks of $O p$ Resolute seems to be due mainly to occupational accidents, with a small number of RTA injuries. A number 
of factors probably contributed to the overall injury rate. For example, the period coincided with the major movement of troops and materiel in early January. Terrain and climate would have been unfamiliar and inhospitable; tasks would have been performed under pressure; and equipment would have needed to be transported and set up under poor work conditions. As the weeks progressed, troop and equipment movements reduced, and the number of injuries showed a corresponding decline. Most of the RTA injuries occurred in weeks 4 and 5 . The number of RTAs as a whole were of great concern for this operation (379 up to week 10), but the small number dealt with at Split probably reflects the facts that most RTAs occurred in $\mathrm{BH}$ and that injuries presented either directly to hospitals or to nearer medical centres. By contrast, the gradual rise in sport injuries would be expected as the workload reduced and corresponding time for recreational activities increased.

The high occurrence of disease in the first 5 weeks had two main contributory factors: the first, the high number of respiratory consultations in week 3 , and the second, the rise in enteric disease consultations in weeks 4 and 5 . 'Other' diseases were also slightly higher in the first few weeks. These increases could have occurred if the practice population had risen correspondingly in this period. However, the figures for MND SW did not show a corresponding rise (G1). The numbers of consultations for respiratory and enteric illnesses showed similar increases in other regions, and it therefore appears that these were real epidemics and were seen in other practices.

From experience, the respiratory epidemic was caused by coryza and a flu-like illness and the enteric disease by gastroenteritis. Crowded military populations have been recognised as highly susceptible to the spread of respiratory pathogens (2) and gastrointestinal diseases have been decisive factors in many military campaigns. Acute common cold type symptoms were a widespread cause of minor morbidity amongst American $(3,4)$ and British (5) troops during Operations Desert Shield and Desert Storm, especially, as in this study, during the period of initial deployment. During Operation Desert Storm diarrhoeal disease, in the initial deployment, was commonly of the mild traveller's type (4), but over all foodborne diarrhoeal illness had a major impact on the manpower and medical resources (3) and drastically reduced the number of front-line personnel available during a critical phase of military operations. In this study there was little food or waterborne diarrheoal illness, perhaps because of the provision of clean water and controlled food sources, as on Operation Restore Hope (6). Bacterial and non-viral diarrhoea were prevalent amongst the local population in Croatia (7) and there could have been a risk of infection in servicemen, especially as the problem was compounded by the widespread disruption of public water and sanitation systems (8) and servicemen were sometimes living in difficult conditions. However, troops did not use local food catering establishments widely and their exposure to indigenous enteric pathogens appears to have been low. The findings of this study appear to confirm that troops living and working in tightly constructed buildings with unavoidable crowding during rapid mobilisation are susceptible to respiratory and diarrhoeal diseases early in the deployment.

The breadth of the 'other disease' category makes interpretation of data very difficult. However, the drug prescribing figures for January, and experience, indicate that, amongst other illnesses, there was a mini-epidemic of eye infections (in week 9 there were 3 cases of iritis).

The number of STDs was very small and a similar observation was made on Operation Desert Storm (4).

There was a relatively high number of consultations with skin disease. Infestations with lice and scabies were common in BH (9), but, in this study, scabies had been found in only 9 patients, one of whom had brought the infestation from his home where his children had been affected. There was no single underlying disease process, but the cold weather and difficult access to washing and shower facilities in some sites led to exacerbation of psoriasis and eczema, which was consistent with previous findings of war dermatology in the Falklands Campaign and on Operation Desert Storm (10).

There were 33 consultations for gynaecological conditions, mostly for repeat prescription of the orato contraceptive pill. Two patients were referred for specialise opinion and one was shown by CT scan to have an ovariar mass. The number of servicewomen in the practic $\Phi_{0}$ population was estimated to be about 100 . The number of consultations suggests that in 6 months the equivalent of all the servicewomen would be seen. As most consultatione are for contraceptive advice, and as the usual period for reviewing those on 'the pill' is 6 months, it would appeas that the estimate of 100 servicewomen would be reasonable (provided all are assumed to be taking 'the pill' and continue taking it on operation).

The distribution of dental consultations was spurious: during weeks 3 to 5 Split was without a dentist. After week 6 a new dental practice was operating and fewer patients therefore presented to the doctor.

There were relatively few psychiatric consultations with a wide spread of conditions: 5 with acute adjustment reactions or depressive symptoms, 3 for bereavement counselling, 3 with longstanding panic disorders, 2 for critical incident debriefing, and 1 each for stress, posttraumatic stress disorder, phobic state, and HIV counselling. The RAF community psychiatric nurse (CPN) saw new patients on the same days set aside for review patients, at 2-3 week intervals, and this could explain the peaks seen in weeks 6 and 9 in the consultation rate for psychiatric illness.

It is noteworthy that drugs commonly used to relieve symptoms of respiratory tract infections were the most widely prescribed drugs and that this was consistent with respiratory infections being the most common complaint. Prescribing costs for these drugs were low compared with other drugs.

The greater numbers of injuries and diseases in the first 
4 or 5 weeks indicate that the early days of this operation were the most critical for health. Although influenza was not proven as a contributing factor in the respiratory epidemic, it was prevalent in the UK when the troops were initially deployed and could have been brought with them. As flu-like illness was a cause of debility at a time when the fighting strength of the forces could be effected by injury as well, it is suggested that immunization against influenza be considered for inclusion in the vaccination requirements for future winter deployments.

\section{REFERENCES}

1. JefFerson TO, Demicheli V, MacMillan AHM. Pilot study of the introduction of the J95 health data collection system. J R Army Med Corps 1996; 142: 2529.

2. Thomas RJ, Cornwill DE, Morton DE, Brooks TJ, HOLMES CK, MAHAJEY WB. Penicillin prophylaxis for streptococcal infections in United States navy and marine corps recruit camps, 1951-1985. Rev Infect Dis 1988; 10: 125-30.

3. Demaio J, Bailey L. A major outbreak of foodborne gastroenteritis among Air Force personnel during Operation Desert Storm. Milit Med 1993; 158: 161164.
4. Hyams KC, Hanson K, Wignall FS, Escamill, OLDFIELD EC. The impact of infectious disease on the health of US troops deployed to the Persian Gulf during Operations Desert Shield and Desert Storm. Clin Infect Dis 1995; 20: 1497-504.

5. SinClair DG, Hepburn NC, Bowen J, Winfield CR. Community acquired pneumonia in the Gulf. $J R$ Army Med Corps 1991; 137: 126-7.

6. Sharp TW, ThORnTON SA, Wallace MR, et al. Diarrheal disease among military personnel during Operation Restore Hope, Somalia, 1992-1993. Am J Trop Med Hyg 1995; 52: 188-93.

7. Cuculic M, Skendzic N, Troselj-Vukic B, BrucicDADO N. An analysis of total expenditure on hospitalized patients with diarrhoeal syndrome. Acta Med Croatica 1994; 48: 89-92.

8. ToOle MJ, Galson S, Brady W. Are wars and public health compatible? Lancet 1993; 341: 1193-96.

9. ACHESON D. Twelfth Report from the Office of the WHO Special Representative (Jan 11, 1993) Zagreb: WHO, 1993.

10. KELLAND R. Falkland and Gulf War medical events. In: Defence Analytical Services Agency. Bath, 1995.

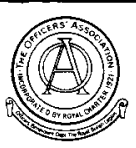

\section{THE OFFICERS' ASSOCIATION RESIDEN'TIAL HOME HUNTLY}

The Officers' Association country home, Huntly, in South Devon is situated in its own extensive landscaped grounds south facing over the Teign estuary and its elegance and style will appeal to the ex-officer of either sex.

It offers the comfort, security and peace of mind of a community while preserving the independence and privacy of its individual residents. It may be likened best to a wellrun Officers' Mess (without the mess duties). Each of the 38 residents has his or her own room, which may be furnished in whole or in part by the resident if desired. The spacious public rooms include a Dining Room, Drawing Room, Library, Snooker Room, Ante-Room, two TV Rooms and each bedroom also has a TV aerial point (no licence fee payable)

Applicants should normally be between 65 and 80 years of age, have held a commission and should not be in need of special nursing care, though the staff includes nurses to deal with minor ailments.

Being supported by the Officers' Association the fees are very modest and do not reflect the high level of comfort and service provided

For further details write or call:

Assistant General Secretary
The Officers' Association
48 Pall Mall, London SW1Y $5 J Y$
Tel: 0171-930 0125
Registered Charity 201321.

